\title{
Analysis of Fos expression in the rat olfactory neurogenic region following single exposure to maternal separation during different neonatal stages
}

\author{
Kamila Fabianová ${ }^{1}$, Monika Závodská ${ }^{1}$, Adam Raček ${ }^{2}$, Andreas Angelidis ${ }^{1}$, Marcela \\ Martončíková ${ }^{1}$ and Enikő Račeková ${ }^{1}$ \\ ${ }^{1}$ Institute of Neurobiology, Slovak Academy of Sciences, Šoltésovej 4-6, 04001, Košice, Slovakia \\ ${ }^{2}$ University of Veterinary Medicine and Pharmacy in Košice, Department of Biology and Genetics, Komenského 41, 04001 , \\ Košice, Slovakia
}

\begin{abstract}
Accumulating evidence confirms that the exposure of neonatal rats to maternal separation (MS) can significantly alter individual processes of postnatal neurogenesis in the olfactory neurogenic region - the subventricular zone (SVZ) and the rostral migratory stream (RMS). To establish the stressful influence of MS on postnatal neurogenesis we have investigated whether altered olfactory environment caused by short-term MS induces expression of Fos protein in the SVZ/RMS and in the olfactory cortical area - anterior olfactory nucleus (AON) of neonatal rats. Pups were separated from mothers for 2 hours at the postnatal days 7, 14 and 21. Immunohistochemically labeled Fos protein was assessed. Our results revealed that single exposure to MS is a stressful event that selectively and in age-dependent manner stimulates cellular activity in the SVZ and AON. A few Fos ${ }^{+}$cells were found in the SVZ of P21 control animals and MS significantly increased their number. This suggests that some SVZ cells are included in the circuitry, which is activated by MS and that these cells have complete equipment for the Fos signal transduction. MS significantly increased the number of $\mathrm{Fos}^{+}$cells in the AON in all age stages examined suggesting that its effect is mediated by olfaction.
\end{abstract}

Key words: Fos protein - Maternal separation - Subventricular zone - Rostral migratory stream - Anterior olfactory nucleus

\section{Introduction}

The subventricular zone (SVZ), which lines most of the lateral wall of the lateral ventricles, persists as a germinal zone into adulthood and functions as the largest region of neurogenesis in the adult brain (Doetsch and AlvarezBuylla 1996). SVZ-derived precursors in rodents migrate tangentially along the rostral migratory stream (RMS) to the olfactory bulb $(\mathrm{OB})$, where they switch from tangential to radial migration and differentiate into local interneurons, within the granular and glomerular layers (Luskin 1993; Lois and Alvarez-Buylla 1994). These interneurons modu-

Correspondence to: Enikő Račeková, Institute of Neurobiology, Slovak Academy of Sciences, Šoltésovej 4-6, 04001, Košice, Slovakia E-mail: racekova@saske.sk late the activity of major output neurons in the $\mathrm{OB}$ and play essential roles in olfactory information processing (Shipley et al. 2004). A dynamic process of adult neurogenesis in the olfactory neurogenic area is regulated by several endogenous as well as exogenous factors such as age, olfactory experience, learning, stress or disease (Zhao et al. 2008; Diaz et al. 2011; Ming and Song 2011). Environmental factors can affect adult neurogenesis at multiple levels, including proliferation, migration, differentiation, integration and survival of newborn cells. However, the mechanisms by which progenitor cells respond to the environmental factors remain unclear.

It is well known that the period of early life is extremely important for brain development, and the developing brain structures are more vulnerable to the effects of exogenous factors. This vulnerability also applies to the 
olfactory neurogenic area, where marked changes in cellular composition (Law et al. 1999; Menezes et al. 2002; Račeková et al. 2003), proliferation activity (Martončíková et al. 2006) and cell migration (Menezes et al. 2002) are evident during the first weeks of life under physiological conditions. Indeed, the SVZ/RMS/OB of neonatal rodents responds to environmental influences, like electromagnetic radiation (Orendáčová et al. 2011), olfactory stimulation (Martončíková et al. 2011; Bonzano et al. 2014) or olfactory deprivation (Cummings and Brunjes 1997; Račeková et al. 2009; Sawada et al. 2011) more intensively than the SVZ/ RMS/OB of adults.

Maternal separation represents a significant intervention in the development of the brain and the behavior of rats. Several studies have clearly demonstrated that maternal separation during the first two - three weeks of life has long-term consequences on endocrine, behavioral and brain development later in life (Caldji et al. 2000; Huot et al. 2001; Daniels et al. 2004). Repeated maternal separation represents a stressful event that affects not only structural brain development but induces changes also in the olfactory neurogenesis (Račeková et al. 2009; Feng et al. 2014; Wu et al. 2014). This can be related to the fact that separation from the mother, besides other effects, causes adverse changes in the olfactory environment of the pups, because of the absence of specific mother derived olfactory stimuli. The effect of single exposure to short-term maternal separation on neurogenesis has not been studied yet.

Hence, we wanted to investigate whether the single exposure to maternal separation during the critical period of the first three postnatal weeks represents a stressful event that could induce immediate changes within the olfactory neurogenic area. In addition, we expand our investigation on the anterior olfactory nucleus (AON), the structure surrounding the rostral part of the RMS. The AON is a part of the olfactory cortex and plays a significant role in olfactory signals processing (Illig 2005). Moreover, recent findings revealed its relation also to the adult neurogenesis as the $\mathrm{AON}$ is involved in regulation of adult-born interneurons integration in the OB (De La Rosa-Prieto et al. 2015).

Nuclear protein Fos is encoded by the immediate early gene $c$-fos, which is rapidly and transiently expressed in neurons in response to stimulation (Morgan and Curran $1989,1991)$. The $c$-fos gene is expressed in the rodent nervous system already during prenatal, as well as during postnatal development. This expression has been found to be restricted to specific regions at late stages of development, particularly to the spinal cord, dorsal root ganglia, and olfactory bulb. The c-fos protein may play a role in the maturation of these structures by activating specific genes (Caubet 1989). Although c-fos could be participating in the regulation of mitosis during early postnatal development of the brain, it can also play an important role in mature brain tissues $(\mathrm{Gu}-$ bits et al. 1988). This method has been used to examine the pattern of brain activation in experimental animals exposed to miscellaneous exogenous factors, especially to stressful or anxiogenic stimuli (Kovács 1998).

The aim of our study was to investigate whether changes in olfactory signals associated with maternal separation will induce activation of Fos protein expression in cells of the SVZ, RMS, AON of neonatal rats.

\section{Material and Methods}

\section{Animals and maternal separation}

In this study, Wistar albino rats aged 7 days (postnatal day 7 (P7); $n=16), 14$ days (P14; $n=16)$ and 21 days (P21; $n=$ 16) of both sexes were used. Animals were bred in the animal facility of the Institute of Neurobiology, Slovak Academy of Sciences.

All experimental procedures used were approved by the Ethical Committee of the Institute of Neurobiology, Slovak Academy of Sciences and the State Veterinary Authority.

On the experimental day, pups from each age group (P7, P14 and P21) were separated from the dam for 120 minutes. Dams were first removed and placed in an adjacent cage. To avoid social isolation, three pups were separated together. They were transferred to a plastic container and placed in an incubator at the temperature consistent with the nest measurements $\left(34^{\circ} \mathrm{C}\right)$. Control rats were reared under the same conditions except maternal separation.

\section{Tissue processing}

Immediately after the finishing of maternal separation, the animals were deeply anesthetized with the mixture of ketamine/xylazine and perfused transcardially with $4 \%$ paraformaldehyde (PFA) in $0.1 \mathrm{M}$ phosphate buffer (PB). The brains were left in the skulls and post-fixed in the same fixative solution overnight at $4^{\circ} \mathrm{C}$. Next day the brains were removed from skulls, post-fixed in PFA overnight, and then cryoprotected with $30 \%$ sucrose in $0.1 \mathrm{M}$ phosphate buffered saline (PBS) for $24 \mathrm{~h}$. After cryoprotection, $30 \mu \mathrm{m}$ thick serial sagittal sections were cut on the cryostat, stored in PBS at $4^{\circ} \mathrm{C}$ and the next day processed for immunohistochemical labeling. Both hemispheres of the brain were used and each was processed by different method.

\section{Fos immunohistochemistry}

Free-floating sections were washed in PBS, incubated in $0.3 \% \mathrm{H}_{2} \mathrm{O}_{2}$ in $0.1 \mathrm{M} \mathrm{PB}$ for 30 minutes, then rinsed in PBS and further incubated in a blocking solution containing $3 \%$ normal goat serum in PBS and $0.25 \%$ Triton X-100, 
for $2 \mathrm{~h}$. Subsequently, the sections were labeled with rabbit polyclonal anti-c-Fos antibody (Oncogene Res. Products, Cambridge, MA, USA; 1:10,000 dilution) on a shaker overnight at room temperature. The following morning, sections were washed six times in PBS and incubated in biotinylated goat anti-rabbit secondary antibody (Abcam, Cambridge, UK), diluted 1:600 in 3\% goat serum in PBS with Triton X-100 for $2 \mathrm{~h}$, then washed three times in PBS and incubated in avidin-biotin complex (ABC elite standard kit, Vector Laboratories, Burlingame, CA, USA). The sections were washed three times in PBS. The reaction product was visualized by $0.01 \%$ hydrogen peroxide and $0.05 \%$ diaminobenzidine (DAB) in $\mathrm{PB}$ for $1-3$ minutes. After being air-dried, the slides were mounted with Entellan (MERCK- Millipore).

\section{Double labeling of Fos producing cells}

In order to reveal the phenotype of Fos producing cells in the SVZ and AON, brain sections of both control and experimental rats were processed for double immunofluorescent labeling. For recognition of astrocytes and neurons, glial fibrillary acidic protein (GFAP) and neuronal nuclear antigen (NeuN) were used, respectively.

The sections were washed three times in PBS and then incubated in 3\% normal goat serum in PBS and $0.25 \%$ Triton X-100 for 2 hours. Subsequently, they were incubated with mixture of two antibodies: either polyclonal rabbit anti-c-Fos (1:10 000; Oncogene) and monoclonal mouse anti GFAP (1:500; Merck Millipore) or polyclonal rabbit anti c-Fos (1:10 000; Oncogene) and monoclonal mouse anti NeuN (1:500; Merck Millipore) for 48 hours at $4^{\circ} \mathrm{C}$. After the incubation, the sections were washed three times in PBS and labeled with mixture of corresponding antibodies: goat anti rabbit Alexa Fluor 594 (1:200; Abcam), goat anti mouse Alexa Flour 488 (1:200, Abcam) for 2 hours at room temperature. Then, the sections were washed three times in PBS. After the processing, the sections were mounted on glass slides, airdried and coverslipped with Fluoromont (SERVA).

\section{Image acquisition, quantitative and statistical analysis}

The number of Fos+ cells was examined in the SVZ, RMS and AON of experimental as well as control rats. Quantitative and statistical analyses were performed as described previously in Fabianová et al. (2014). Briefly, to explore Fos positivity in the RMS and AON, only sections in which the whole extent of the RMS was visible were evaluated (six-eight sections for each animal). The caudal limit of the RMS was defined as the point at which the lumen of the lateral ventricle opens up and the rostral limit as the point at which the RMS ends in the OB subependymal layer. Images of individual sections were taken using digital camera (Olympus DP72) connected to light microscope (Olympus BX51) with a $20 \times$ objective. An optical graticule was used to manually quantify the number of Fos+ neurons in each examined region. In the SVZ $200 \times$ $200 \mu \mathrm{m}$ area was evaluated and in the RMS and AON $50 \times$ $50 \mu \mathrm{m}$ area was evaluated. The graticule was placed in a fixed position in the explored area relative to known anatomical landmarks. Only darkly labeled oval-shaped nuclei that fell within the grid were counted. Images for the analysis of double-immunolabeled cells were acquired with digital camera of the fluorescent microscope with $40 \times$ objective (Olympus Reflected Fluorescent System) using "narrow blue" (Em. 515+) and "narrow green" (Em. 590+) filters. The images were captured with Quick PHOTO MICRO 2.3 software and processed (merged) by Adobe Photoshop 7.0. The results of all experiments were expressed as mean \pm standard error of the mean (SEM), and data were analyzed by analysis of variances (ANOVA) followed by Tukey-Kramer test using GraphPad Prism 5.0 statistical analysis software, with $p$-values less than 0.05 considered statistically significant.

\section{Results}

\section{Fos expression in the subventricular zone}

Our results have shown that single exposure of rat pups of different ages to maternal separation resulted in age-specific selective enhancement of Fos protein expression in the olfactory neurogenic region - in the SVZ, as well as in the AON.

We have observed that there were no Fos+ cells in the SVZ of P7 and P14 control rats and even maternal separation did not induce the appearance of Fos+ cells in these age stages. However, in P21 control rats (Fig. 1A), a few Fos+ cells were detected in the anterior part of the lateral ventricle wall and occasionally in the SVZ. Single exposure of age-matched animals to maternal separation resulted in a significant increase of the number of Fos + cells in their SVZ $(p<0.001)$ (Fig. 1B). The results of quantitative analysis are summarized in the Table 1.

Table 1. Number of Fos positive cells within the $200 \times 200 \mu \mathrm{m}^{2}$ area of the SVZ in P7, P14 and P21 control animals and in P7, P14 and P21 experimental animals

\begin{tabular}{lcc}
\hline Group & $\begin{array}{c}\text { Control animals } \\
(n=8)\end{array}$ & $\begin{array}{c}\text { MS } \\
(n=8)\end{array}$ \\
\hline P7 & 0 & 0 \\
P14 & 0 & 0 \\
P21 & $0.42 \pm 0.13$ & $1.98 \pm 0.26^{* * *}$ \\
\hline
\end{tabular}

Data are shown as mean \pm SEM. Statistical significance of differences between experimental and control group. ${ }^{* *} p<0.001$; degrees of freedom: $F=37.82$. SVZ, subventricular zone; MS, maternal separation; P7, 14, 21 - postnatal day 7, 14, 21. 


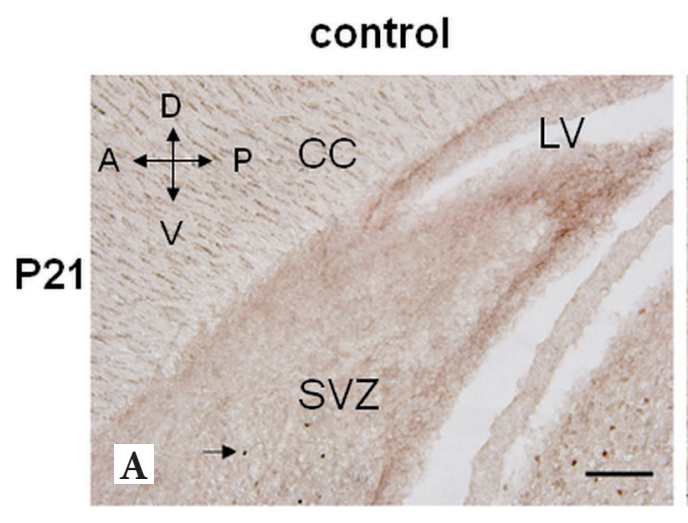

maternal separation

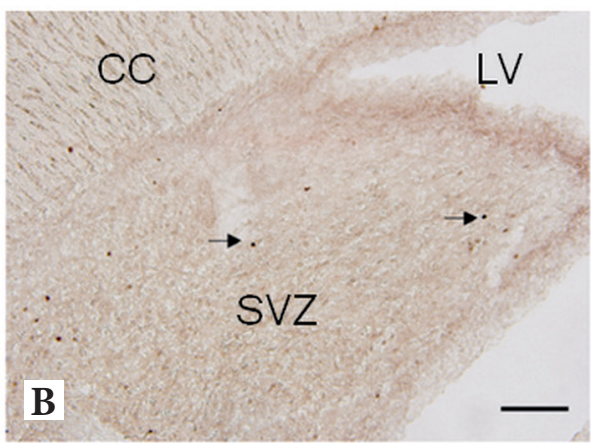

Figure 1. Fos immunoreactivity in the subventricular zone. A few Fos+ cells (arrows) are found in P21 control animals (A). Maternally separated P21 rats (B) demonstrate an increase of the number of Fos+ cells (arrows). Scale bar $50 \mu \mathrm{m}$. Structures: CC, corpus callosum; LV, lateral ventricle; SVZ, subventricular zone. Directions: A, anterior; $\mathrm{P}$, posterior; $\mathrm{D}$, dorsal; $\mathrm{V}$, ventral.
To analyze the phenotype of Fos+ cells in the SVZ, we have used double labeling for Fos and GFAP and for Fos and NeuN for recognition of astrocytes and neurons, respectively. There was no evidence for Fos and GFAP co-labeling. In contrast, double-labeling immunofluorescence against Fos and NeuN showed co-localization of both markers within the same cells (Fig. 2) indicating that Fos+ cells of the SVZ are mature neurons.

Fos expression in the rostral migratory stream and in the anterior olfactory nucleus

To detect Fos expression in cells of the RMS, the whole extent of the migratory pathway was analyzed in detail. Light microscopic observation showed that there were no Fos+ cells in any part of the RMS neither in control animals nor in maternally separated rats in any age stages examined (Fig. 3). On the other hand, maternal separation caused marked changes in Fos positivity in the AON (Fig. 3). The AON has substantial connections with other olfactory areas and is typically divided into two major regions: pars externa and pars principalis (Kay et al. 2011).
We have focused the Fos analysis on the pars principalis, which is localized in close vicinity of the RMS and almost strictly follows the course of its rostral part. Whilst there were no Fos + cells present in any part of pars principalis of the control $\mathrm{P} 7$ rats (Fig. 3A), maternal separation in $\mathrm{P} 7$ induced the appearance of the small population of labeled cells in this part of the AON (Fig. 3B). In pars principalis of P14 control animals, a few sharply bounded Fos+ cells were observed (Fig. 3C) and in P21 control animals this region was characteristic by the presence of numerous Fos+ cells (Fig. 3E). As can be seen on the figure 3D and 3F, maternal separation in P14 and P21 increased the amount of Fos+ cells in pars principalis. Subsequent quantitative analysis revealed statistical significance of all these increases $(p<$ 0.001) (Fig. 4).

Regarding the phenotype of Fos+ cells in the AON, none of them expressed the marker for astrocytes (GFAP) (Fig. $5 A)$. Fos+ cells were co-labeled with NeuN confirming the neuronal phenotype of these cells (Fig. 5B).

The obtained data indicate that during early postnatal development the pattern of Fos expression within the SVZ and AON of control animals undergoes dynamic changes.

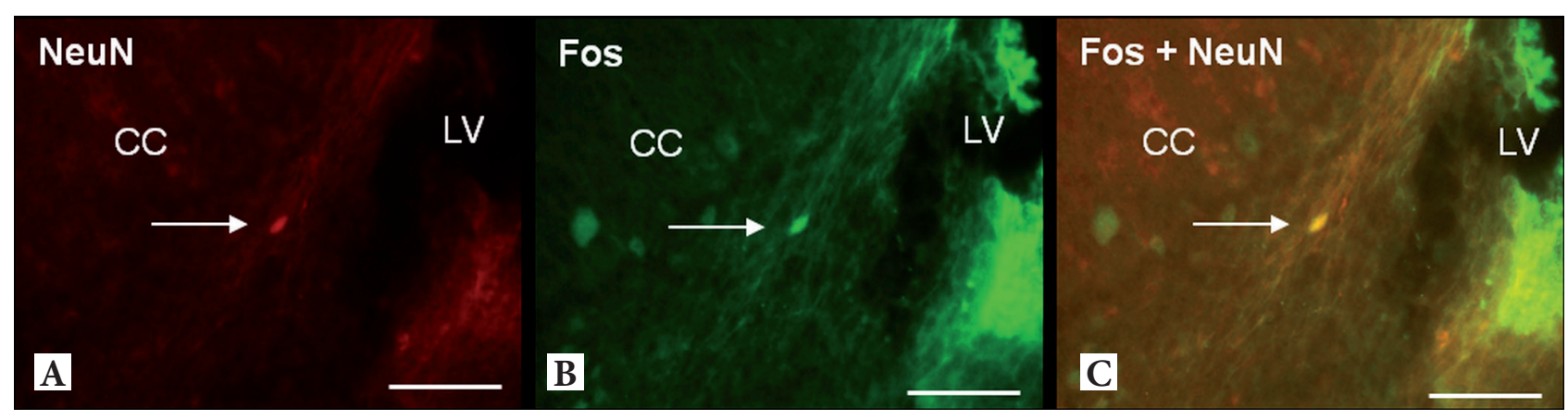

Figure 2. Phenotype of Fos+ cells in the SVZ of P21 control rat. A, B. Images showing double labeling for NeuN (red; A) and Fos (green; B). C. Fos+ cells in the SVZ are neurons. Arrow indicates colocalization of Fos and NeuN. Scale bar $50 \mu \mathrm{m}$. Structures: CC, corpus callosum; LV, lateral ventricle. 


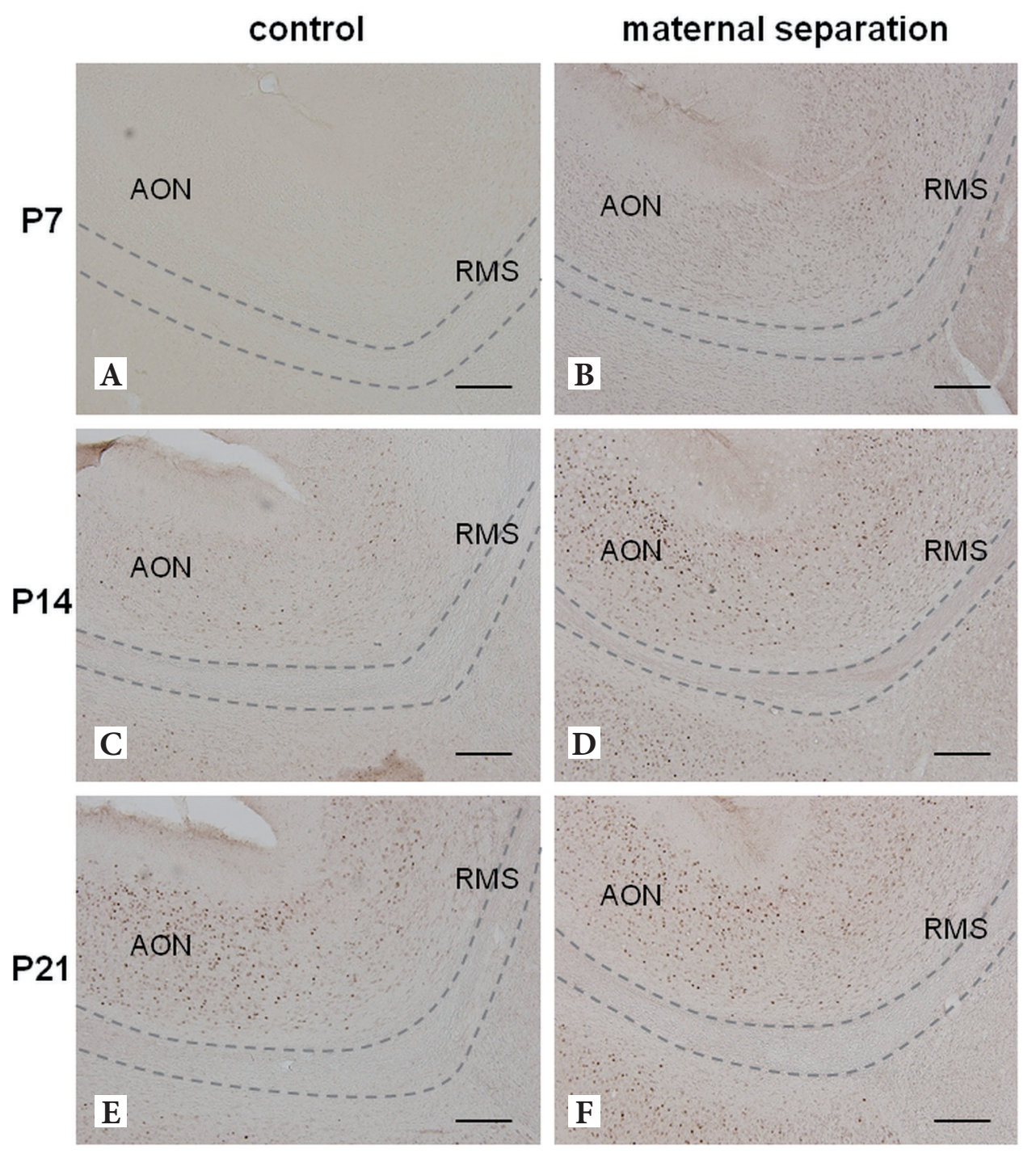

Figure 3. Fos immunoreactivity in the rostral migratory stream (RMS) and in the anterior olfactory nucleus (AON). A. -F. Photomicrographs of parasagittal sections of the RMS of control groups (left column) and maternally separated groups (right column) showing the distribution of Fos+ cells. Fos+ cells are visible as brown stained nuclei. There is no Fos positivity within the RMS (the RMS is bordered by dashed lines) of both control and experimental groups. Noteworthy, the structure of the olfactory cortex that closely surrounds the RMS - pars principalis of the AON, contains a number of Fos+ cells (B-F) in striking contrast to the RMS. Fos positivity in the $\mathrm{AON}$ is noticeably higher after single short-time exposure to maternal separation in all age groups (right column). Scale bar $50 \mu \mathrm{m}$.

Quantification of Fos+ cells in these areas showed that the examined regions respond to maternal odor absence differently and also in an age-dependent manner (Table 2).

Table 2. Fos like immunoreactivity in the SVZ, RMS and AON pars principalis

\begin{tabular}{lccc}
\hline \multicolumn{3}{c}{ Group } \\
\hline & $\begin{array}{c}\text { P7 } \\
\text { control/MS }\end{array}$ & $\begin{array}{c}\text { P14 } \\
\text { control/MS }\end{array}$ & $\begin{array}{c}\text { P21 } \\
\text { control/MS }\end{array}$ \\
\hline SVZ & $0 / 0$ & $0 / 0$ & $* / * *$ \\
RMS & $0 / 0$ & $0 / 0$ & $0 / 0$ \\
AON & $0 / *$ & $* / *$ & $* / *$ \\
\hline
\end{tabular}

Symbols indicate the amount of Fos protein. 0, no staining; ${ }^{*}$ low level staining; ${ }^{* *}$ medium level staining. SVZ, subventricular zone; RMS, rostral migratory stream; AON, anterior olfactory nucleus; MS, maternal separation; P7, 14, 21 - postnatal day 7, 14, 21.

\section{Discussion}

The expression of immediate early genes is often used as a marker of neuronal activity. The present study was designed to investigate whether single exposure of neonatal rats to maternal separation can induce Fos protein expression in cells of olfactory neurogenic region - the SVZ/RMS. Because Fos protein labeling is widely employed in assessing patterns of evoked activity in the olfactory system (Filipkowski 2000), we have also used it for visualization of activity in the olfactory cortical structure - the AON.

Fos expression in the subventricular zone and in the rostral migratory stream

Expression of immediate early genes was used to study new neurons in the adult dentate gyrus (Jessberger and Kemper- 
mann 2013). Regarding the olfactory neurogenic region, to our best knowledge, complex analysis of Fos production in the SVZ/RMS has not been provided until now.

Our results have shown that there were no Fos+ cells present in the SVZ of P7 and P14 control rats and maternal separation also did not induce the appearance of them at these ages. However, we have observed a few Fos+ cells in the SVZ at P21 in control rats, and quantitative analysis showed their significant increase following maternal separation. Rare occurrence of Fos + cells points to the possibility that probably only some cells of the SVZ have the complete equipment for the Fos signal transduction cascade. Similar findings have been reported in our previous study dealing with the analysis of Fos expression in the SVZ following the exposure of neonatal rats to whole body electromagnetic radiation (EMR) (Orendáčová et al. 2011). In that experiment we have found that short-duration exposure of neonatal P7 rats to EMR induces increased Fos immunoreactivity selectively in cells of the SVZ. It is interesting that while exposure of $\mathrm{P} 7$ rats to maternal separation did not cause Fos production in the SVZ, exposure to EMR enhanced neuronal activity in the SVZ of rats of the same age, as indicated by Fos expression. Based on these findings, we can assume that the SVZ cells appear to be more sensitive to the single EMR application than to maternal separation, and that the production of Fos protein of the SVZ is dependent on the type of stressor.

Our results suggest that Fos+ cells of the SVZ are neurons. However, the subpopulation of Fos+ neurons in the SVZ remains unclear. As the only known neurons residing in the SVZ are nitrergic cells (Račeková et al. 2003) and the most recently described population of choline acetyltransferase positive neurons (Paez-Gonzales et al. 2014), we hypothesize that both these phenotypes could express Fos. However, further study is needed for the exact determination of the phenotype of Fos+ cells within the SVZ.

The physiological consequence of c-fos signal transduction in the SVZ remains to be explained. Since the possibility of regulating neurogenesis through neuronal circuits has only recently begun to be investigated (Song et al. 2016), it would be too early to speculate about connectivity of Fos+ cells. One possible explanation of the role of Fos protein in the neurogenic area could be related to the importance of Fos protein in cell proliferation during development (Velazquez et al. 2015). Indeed, the increase of the number of Fos+ cells in the SVZ at P21 coincidences with previously observed decrease of proliferating cells in olfactory neurogenic areas following maternal separation (Račeková et al. 2009).

The migratory pathway, by which the SVZ cells reach the $\mathrm{OB}$, also contains a number of young postmitotic neurons (Jankovski and Sotelo 1996) and small population of nitrergic neurons (Račeková et al. 2003), which could be a potential source of Fos protein. Nevertheless, in our experiment we did not find any Fos+ cells neither in the RMS of control nor in the RMS of maternally separated animals in any neonatal age stages examined. Similar results were obtained in our previous study (Fabianová et al. 2014), where we showed the absence of Fos+ cells even in the RMS of intact adult rats, as well as in the RMS of rats stimulated with cat odor. Nevertheless, the exposure of rats to the artificial odor stimuli induced Fos protein expression in certain cells of the RMS (Fabianová et al. 2014). These findings suggest that the RMS activation is led only by some specific olfactory events. This may also indicate that the RMS is not involved in the circuitry, which is activated by maternal separation. Another explanation for the absent of Fos positivity in the RMS of control and maternally separated P7, P14 and P21 rats may be related with the age of animals. In this context, it seems reasonable to suggest that the cells of the RMS of neonatal rats do not contain complete equipment for the Fos signal transduction cascade. Indeed, it is well established that the RMS belongs to the brain structures, which undergo a remarkable anatomical reorganization after the birth. During early postnatal development, besides quantitative differences related to the RMS thickness and shape (Altman 1969; Pencea et al. 2001; Martončíková et al. 2006), and the olfactory ventricle obliteration (Peretto et al. 1999), marked qualitative changes occur in the pattern of the RMS cell migration (Doetsch 1997; Peretto et al. 1997), proliferation activity (Martončíková et al. 2006) or differentiation of neuronal precursors (Law et al. 1999). So, it is quite possible that the development of Fos signal transduction cascade in rodent RMS is completed only after the third week of life. According to a study of Gubits and co-workers, c-fos gene expression

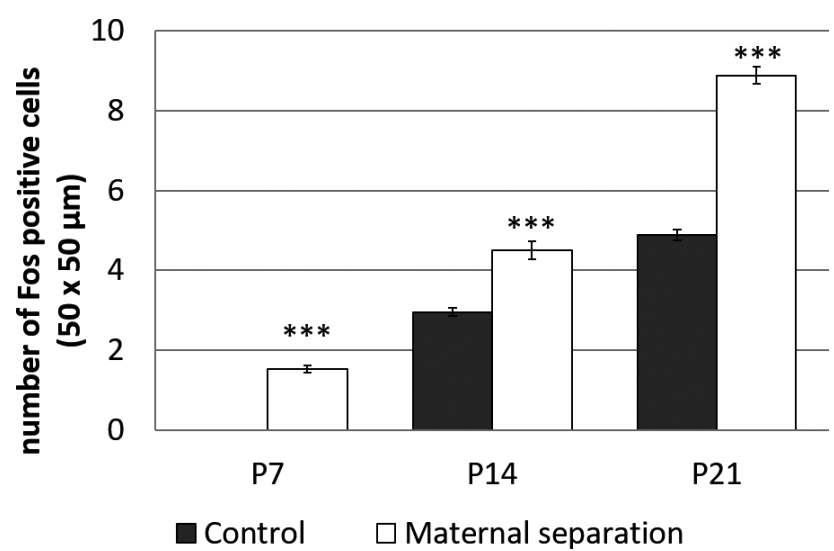

Figure 4. Number of Fos+ cells within $50 \times 50 \mu \mathrm{m}$ area in the anterior olfactory nucleus (AON) pars principalis of the P7, P14 and P21 control rats, as well as in P7, P14 and P21 maternally separated rats. The graph shows significant increases of Fos+ cells in the AON of maternally separated rats. Data are shown as mean \pm SEM. Statistical significance of differences between experimental and control groups: ${ }^{* *} p<0.001$; degrees of freedom: $\mathrm{F}=354.9$. 


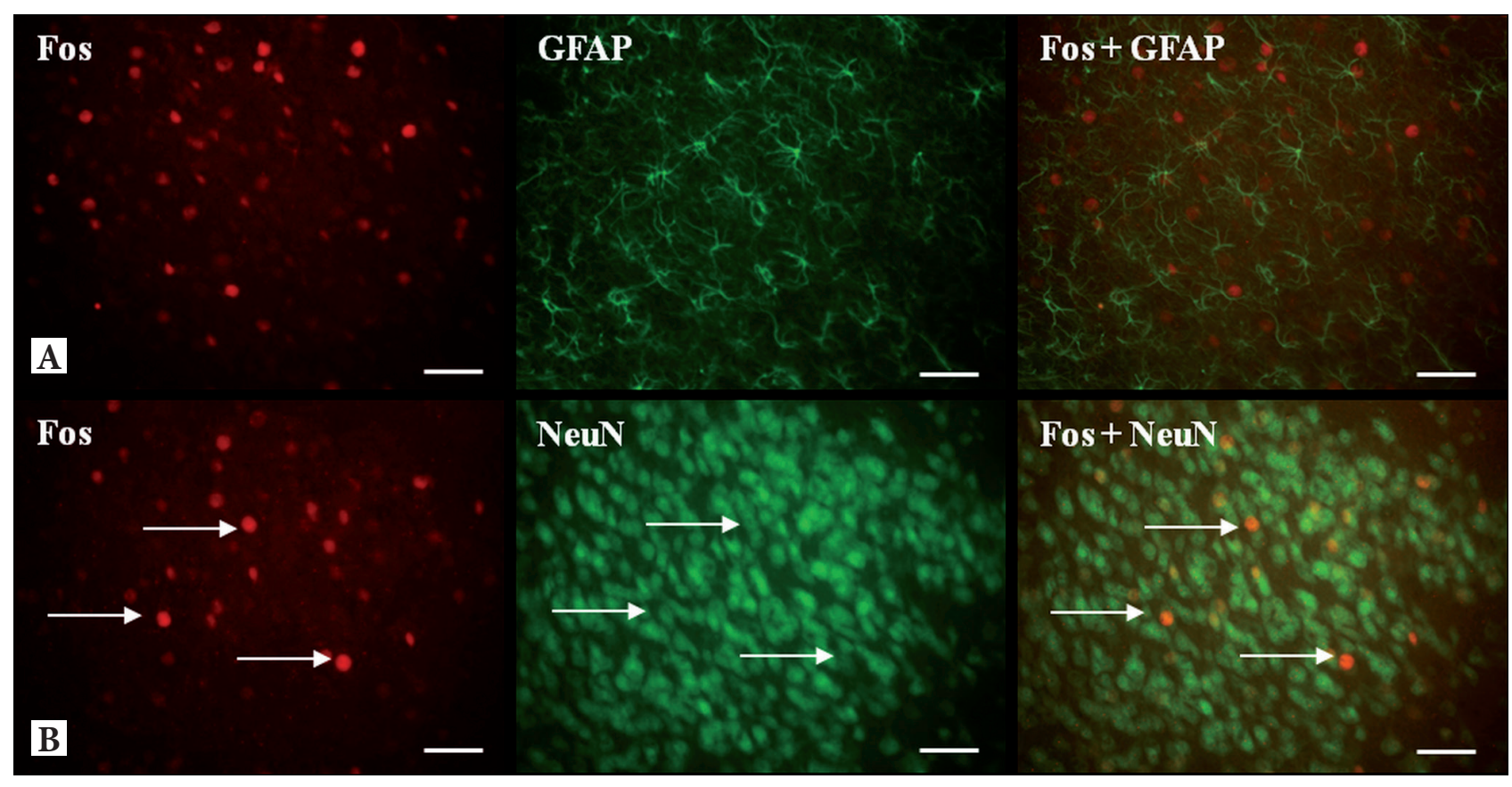

Figure 5. Phenotype of Fos+ cells in the anterior olfactory nucleus (AON) of P21 control rat. Photomicrographs showing double labeling for Fos and either GFAP (A) or NeuN (B). A. No cells in the AON were found to be labeled for both Fos protein (red) and GFAP (green). B. Note the colocalization of Fos (red) and neuronal marker NeuN (green) in cells on merged image. Arrows point to double-labeled cells with neuronal phenotype. Scale bar $50 \mu \mathrm{m}$.

in the rat brain varies in both amount and location during early development. Levels of c-fos mRNA are considerably elevated in the cerebellum and parietal cortex at P20 and in the whole brain after P30 (Gubits et al. 1988). Based on our results, we can assume that in the rat RMS c-fos mRNA is present only after P21.

The obtained pattern of Fos positivity also suggests that the SVZ and RMS of neonatal rats are not uniform in the terms of functionality. Fos expression in the SVZ and its absence in the RMS indicates that there are some differences in facilities of cells between the SVZ and RMS of neonatal rats. Moreover, different reaction of the SVZ and RMS to maternal separation can be due to different stress threshold of the cells in these regions. Thus the SVZ cells can be more sensitive to stress induced by maternal separation in comparison with the RMS cells.

\section{Fos expression in the anterior olfactory nucleus}

While there were no Fos+ cells in the RMS, we have detected them in the AON, a structure that is closely adjacent to the migratory pathway. The $\mathrm{AON}$ is an olfactory cortical structure that has reciprocal connections with both the olfactory bulb and piriform cortex (Illig and Eudy 2009). For this reason, expression of Fos protein in this structure is obviously evoked by odor stimulation (Kay et al. 2011).
Postnatal disruption of the mother-infant interaction is not a typical model of odor stimulation, but involvement of olfactory system in mediation of the separation-evoked effects has been suggested formerly (Hofer 1975). We have observed increased Fos expression and premature appearance of Fos+ cells in the AON of maternally separated rats. Evoked activity in this structure that plays a key role in odor information processing confirms that olfaction mediated the effects evoked by maternal separation.

The AON has been shown to have a relation also to adult neurogenesis. Generation of new neurons has been detected in the AON, albeit at relatively lower levels than that found in the OB (Shapiro et al. 2009). Moreover, it has been shown that the AON is involved in regulation of newborn interneurons integration into the OB (De La Rosa-Prieto et al. 2015). Taken into account the importance of Fos protein in cell proliferation and differentiation (Velazquez et al. 2015), the induced Fos expression in the AON could influence neurogenesis in this structure.

\section{Conclusion}

The results of the present study contribute to the understanding of the mechanisms involved in the extrinsic regulation of postnatal neurogenesis by evaluation of Fos protein induc- 
tion in the SVZ/RMS of neonatal rats following maternal separation. The novel finding is demonstration of Fos protein expression in some cells of the SVZ. Single separation of rat pups from their mother on the postnatal day 21 increased Fos protein expression in the SVZ. Contrary to this, no Fos positivity was found neither in the RMS of control nor maternally separated rats in any age stages examined. It indicates that the SVZ and RMS are not uniform in the terms of functionality. On the other hand, following maternal separation, we have observed significant increase of Fos expression in the AON - the olfactory cortical structure which is also involved in regulation of postnatal neurogenesis. Enhancement of Fos expression in the AON after the maternal separation suggests that this effect is mediated by the olfaction.

Acknowledgements. This work was supported by the grants VEGA: 2/0069/15 and 2/0159/17, and by the Research and Development Operational Programme funded by the ERDF No. ITMS 26220220202. We would like to thank Jolana Kalinčáková for her technical assistance.

\section{References}

Altman J (1969): Autoradiographic and histological studies of postnatal neurogenesis. IV. Cell proliferation and migration in the anterior forebrain, with special reference to persisting neurogenesis in the olfactory bulb. J. Comp. Neurol. 137, 433-457 https://doi.org/10.1002/cne.901370404

Bonzano S, Bovetti S, Fasolo A, Peretto P, De Marchis S (2014): Odour enrichment increases adult-born dopaminergic neurons in the mouse olfactory bulb. Eur. J. Neurosci. 40, 3450-3457 https://doi.org/10.1111/ejn.12724

Caldji C, Francis D, Sharma S, Plotsky PM, Meaney MJ (2000): The effects of early rearing enviroment on the development of GABAA and central benzodiazepine receptor levels and novelty-induced fearfulness in the rat. Neuropsychopharmacol. 22, 219-229 https://doi.org/10.1016/S0893-133X(99)00110-4

Caubet JF (1989): c-Fos proto-oncogene expression in the nervous system during mouse development. Mol. Cell. Biol. 9, 2269-2272

https://doi.org/10.1128/MCB.9.5.2269

Cummings DM, Brunjes PC (1997): The effects of variable periods of functional deprivation on olfactory bulb development in rats. Exp. Neurol. 148, 360-366 https://doi.org/10.1006/exnr.1997.6660

Daniels WM, Pietersen CY, Carstens ME, Stein DJ (2004): Maternal separation in rats leads to anxiety-like behavior and a blunted ACTH response and altered neurotransmitter levels in response to a subsequent stressor. Metab. Brain Dis. 19, 3-14 https://doi.org/10.1023/B:MEBR.0000027412.19664.b3

De La Rosa-Prieto C, De Moya-Pinilla M, Saiz-Sanchez D, UbedaBanon I, Arzate DM, Flores-Cuadrado A, Liberia T, Crespo C, Martinez-Marcos A (2015): Olfactory and cortical projec- tions to bulbar and hippocampal adult-born neurons. Front. Neuroanat. 9, 1-10

https://doi.org/10.3389/fnana.2015.00004

Díaz D, Recio JS, Baltanás FC, Gómez C, Weruaga E, Alonso JR (2011): Long-lasting changes in the anatomy of the olfactory bulb after ionizing irradiation and bone marrow transplantation. Neuroscience 173, 190-205

https://doi.org/10.1016/j.neuroscience.2010.10.082

Doetsch F, Alvarez-Buylla A (1996): Network of tangential pathways for neuronal migration in adult mammalian brain. Proc. Natl. Acad. Sci. USA 93, 14895-14900 https://doi.org/10.1073/pnas.93.25.14895

Doetsch F, García-Verdugo JM, Alvarez-Buylla A (1997): Cellular composition and threedimensional organization of the subventricular germinal zone in the adult mammalian brain. J. Neurosci. 17, 5046-5061 https://doi.org/10.1523/JNEUROSCI.17-13-05046.1997

Fabianová K, Martončíková M, Fabian D, Blaško J, Račeková E (2014): Diverse effect of different odor stimuli on behavior and Fos protein production in the olfactory system neurogenic region of adult rats. Behav. Brain Res. 265, 38-48 https://doi.org/10.1016/j.bbr.2014.01.023

Feng M, Sheng G, Li Z, Wang J, Ren K, Jin X, Jiang K (2014): Postnatal maternal separation enhances tonic GABA current of cortical layer 5 pyramidal neurons in juvenile rats and promotes genesis of GABAergic neurons in neocortical molecular layer and subventricular zone in adult rats. Behav. Brain Res. 260, 74-82 https://doi.org/10.1016/j.bbr.2013.11.040

Filipkowski RK (2000): Inducing gene expression in barrel cortex-focus on immediate early genes. Acta Neurobiol. Exp. 60, 411-418

Gubits RM, Hazelton JL, Simantov R (1988): Variations in c-fos gene expression during rat brain development. Brain Res. 427, 197-201 https://doi.org/10.1016/0169-328X(88)90067-8

Hofer MA (1975): Studies on how early maternal separation produces behavioral change in young rats. Psychosom. Med. 37, 245-264 https://doi.org/10.1097/00006842-197505000-00003

Huot RL, Thrivikraman KV, Meaney MJ, Plotsky PM (2001): Development of adult ethanol preference and anxiety as a consequence of neonatal maternal separation in Long Evans rats and reversal with antidepressant treatment. Psychopharmacology 158, 366-373 https://doi.org/10.1007/s002130100701

Illig KR (2005): Projections from orbitofrontal cortex to anterior piriform cortex in the rat suggest a role in olfactory information processing. J. Comp. Neurol. 488, 224-231 https://doi.org/10.1002/cne.20595

Illig KR, Eudy JD (2009): Contralateral projections of the rat anterior olfactory nucleus. J. Comp. Neurol. 512, 115-123 https://doi.org/10.1002/cne.21900

Jankovski A, Sotelo C (1996): Subventricular zone-olfactory bulb migratory pathway in the adult mouse: Cellular composition and specificity as determined by heterochronic and heterotopic transplantation. J. Comp. Neurol. 371, 376-396 https://doi.org/10.1002/(SICI)1096-9861(19960729)371:3<376::AID-CNE3>3.0.CO;2-\# 
Jessberger S, Kempermann G (2013): Adult-born hippocampal neurons mature into activity-dependent responsiveness. Eur. J. Neurosci. 18, 2707-2712 https://doi.org/10.1111/j.1460-9568.2003.02986.x

Kay RB, Meyer EA, Illig KR, Brunjes PC (2011): Spatial distribution of neuronal activity in the anterior olfactory nucleus evoked by odor and electrical stimulation. J. Comp. Neurol. 519, 277-289 https://doi.org/10.1002/cne.22519

Kovács KJ (1998): c-Fos as a transcription factor: a stressful (re) view from a functional map. Neurochem. Int. 33, 287-297 https://doi.org/10.1016/S0197-0186(98)00023-0

Law AK, Pencea V, Buck CR, Luskin MB (1999): Neurogenesis and neuronal migration in the neonatal rat forebrain anterior subventricular zone do not require GFAP-positive astrocytes. Dev. Biol. 216, 622-634 https://doi.org/10.1006/dbio.1999.9498

Lois C, Alvarez-Buylla A (1994): Long-distance neuronal migration in the adult mammalian brain. Science 264, 1145-1148 https://doi.org/10.1126/science.8178174

Luskin MB (1993): Restricted proliferation and migration of postnatally generated neurons derived from the forebrain subventricular zone. Neuron 11, 173-189 https://doi.org/10.1016/0896-6273(93)90281-U

Martončíková M, Račeková E, Orendáčová J (2006): The number of proliferating cells in the rostral migratory stream of rat during the first postnatal month. Cell. Mol. Neurobiol. 26, 1453-1461 https://doi.org/10.1007/s10571-006-9039-7

Martončíková M, Lievajová K, Orendáčová J, Blaško J, Račeková E (2011): Odor enrichment influences neurogenesis in the rostral migratory stream of young rats. Acta Histochem. 113, 326-332 https://doi.org/10.1016/j.acthis.2010.01.002

Menezes JR, Marins M, Alves JA, Froes MM, Hedin-Pereira C (2002): Cell migration in the postnatal subventricular zone. Braz. J. Med. Biol. Res. 35, 1411-1421 https://doi.org/10.1590/S0100-879X2002001200002

Ming GL, Song H (2011): Adult neurogenesis in the mammalian brain: significant answers and significant questions. Neuron 70, 687-702 https://doi.org/10.1016/j.neuron.2011.05.001

Morgan JI, Curran T (1989): Stimulus-transcription coupling in neurons: role of cellular immediate-early genes. Trends Neurosci. 12, 459-462 https://doi.org/10.1016/0166-2236(89)90096-9

Morgan JI, Curran T (1991): Stimulus-transcription coupling in the nervous system: involvement of the inducible proto-oncogenes fos and jun. Annu. Rev. Neurosci. 14, 421-451 https://doi.org/10.1146/annurev.ne.14.030191.002225

Orendáčová J, Orendáč $M$, Mojžiš M, Labun J, Martončíková $M$, Saganová K, Lievajová K, Blaško J, Abdiová H, Gálik J, Račeková E (2011): Effects of short-duration electromagnetic radiation on early postnatal neurogenesis in rats: Fos and NADPH-d histochemical studies. Acta Histochem. 113, 723-728 https://doi.org/10.1016/j.acthis.2010.09.009

Paez-Gonzales P, Asrican B, Rodriquez E, Kuo CHT (2014): Identification of distinct ChAT+ neurons and activity-dependent control of postnatal SVZ neurogenesis. Nat. Neurosci. 17, 934-942 https://doi.org/10.1038/nn.3734

Pencea V, Bingaman KD, Freedman LJ, Luskin MB (2001): Neurogenesis in the subventricular zone and rostral migratory stream of the neonatal and adult primate forebrain. Exp. Neurol. 172, $1-16$ https://doi.org/10.1006/exnr.2001.7768

Peretto P, Merighi A, Fasolo A, Bonfanti L (1997): Glial tubes in the rostral migratory stream of the adult rat. Brain Res. Bull. 42, 9-21 https://doi.org/10.1016/S0361-9230(96)00116-5

Peretto P, Merighi A, Fasolo A, Bonfanti L (1999): The subependymal layer in rodents: a site of structural plasticity and cell migration in the adult mammalian brain. Brain Res. Bull. 49, 221-243 https://doi.org/10.1016/S0361-9230(99)00037-4

Račeková E, Orendáčová J, Martončíková M, Vanický I (2003): NADPH-diaphorase positivity in the rostral migratory stream of the developing rat. Brain Res. Dev. Brain Res. 146, 131-134 https://doi.org/10.1016/j.devbrainres.2003.09.014

Račeková E, Lievajová K, Danko J, Martončíková M, Flešárová S, Almášiová V, Orendáčová J (2009): Maternal separation induced alterations of neurogenesis in the rat rostral migratory stream. Cell. Mol. Neurobiol. 29, 811-819 https://doi.org/10.1007/s10571-009-9362-x

Sawada M, Kaneko N, Inada H, Wake H, Kato Y, Yanagawa Y, Kobayashi K, Nemoto T, Nabekura J, Sawamoto K (2011): Sensory input regulates spatial and subtype-specific patterns of neuronal turnover in the adult olfactory bulb. J. Neurosci. 31, 11587-11596 https://doi.org/10.1523/JNEUROSCI.0614-11.2011

Shapiro LA, Kwan NG, Zhou QY, Ribak CE (2009): SVZ-derived newly generated neurons populate several olfactory and limbic forebrain regions. Epilepsy Behav. 14, 74-80 https://doi.org/10.1016/j.yebeh.2008.09.011

Shipley MT, Ennis M, Puche AC (2004): The olfactory system. In: The Rat Nervous System. (Ed. Paxinos G), pp. 921-962, Elsevier Academic Press, San Diego, USA https://doi.org/10.1016/B978-012547638-6/50030-4

Song J, Olsen RHJ, Sun J, Ming G, Song H (2016): Neuronal circuitry mechanisms regulating adult mammalian neurogenesis. Cold Spring Harb. Perspect. Biol. 8, a018937 https://doi.org/10.1101/cshperspect.a018937

Velazquez FN, Prucca CG, Etienne O, D'Astolfo DS, Silvestre DC, Boussin FD, Caputto BL (2015): Brain development in impaired in c-fos -/- mice. Oncotarget. 6, 16883-16901 https://doi.org/10.18632/oncotarget.4527

Wu Y, Patchev AV, Daniel G, Almeida OF, Spengler D (2014): Earlylife stress reduces DNA methylation of the Pomc gene in male mice. Endocrinology 155, 1751-1762 https://doi.org/10.1210/en.2013-1868

Zhao Ch, Deng W, Gage FH (2008): Mechanisms and functional implications of adult neurogenesis. Cell 132, 645-660 https://doi.org/10.1016/j.cell.2008.01.033

Received: August 1, 2017

Final version accepted: November 9, 2017 